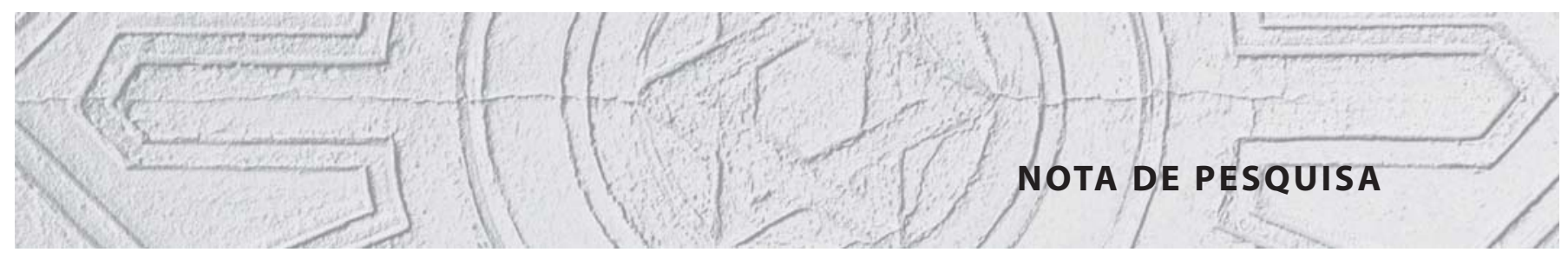

\title{
Entre o moderno e o rústico: a territorialização da medicina preventiva no médio rio Doce
}

\author{
Between the modern and the rustic: the territorialization of \\ preventive medicine in the middle Doce River
}

\section{Patrícia Falco Genovez \\ Professora do curso de História e do Mestrado em Gestão Integrada doTerritório/Universidade Vale do Rio Doce (Univale). \\ Universidade Vale do Rio Doce Rua Israel Pinheiro, 2000 \\ Núcleo de Estudos Históricos e \\ Territoriais, bloco PVA, sala 03 \\ 35020-220 - Governador Valadares \\ - MG - Brasil \\ patricia.genovez@superig.com.br}

\section{Maria Terezinha Bretas Vilarino \\ Professora do curso de História/ Univale. \\ Universidade Vale do Rio Doce Rua Israel Pinheiro, 2000 Núcleo de Estudos Históricos e Territoriais, bloco PVA, sala 03 35020-220 - Governador Valadares - MG - Brasil \\ tevilarino@univale.br}

\section{José Luiz Cazarotto}

Professor de Psicologia/Centro Universitário Salesiano de São Paulo.

Rua Pio XI, 1100

05060-001 - São Paulo - SP - Brasil

jlcazarotto@uol.com.br
GENOVEZ, Patrícia Falco; VILARINO, Maria Terezinha Bretas; CAZAROTTO, José Luiz. Entre o moderno e o rústico: a territorialização da medicina preventiva no médio rio Doce. História, Ciências, Saúde Manguinhos, Rio de Janeiro, v.19, n.4, out-dez, 2012, p.1333-1339.

\section{Resumo}

Na historiografia recente sobre o médio rio Doce reconhece-se a ação do Serviço Especial de Saúde Pública como impulsionadora do desenvolvimento regional entre 1940 e 1950 . Não se aprofundam, contudo, atividade e métodos utilizados. Verificar a concepção de saúde e de desenvolvimento subjacente a suas práticas e as condições de sua manutenção é fundamental para avaliar o papel exercido pelo serviço. Sua contribuição deve ser considerada na relação estabelecida com a população, para a qual suas ações trouxeram desenvolvimento, embora tenham alterado práticas de saúde, costumes e valores culturais, reorganizado o espaço, interferindo nas temporalidades estabelecidas e redefinindo as territorialidades exercidas.

Palavras-chave: Serviço Especial de Saúde Pública; medicina preventiva; médio rio Doce; cultura; territorialidades.

\section{Abstract}

Recent historiography on the middle Doce River recognizes the work of Brazil's Special Public Health Service as one of the factors of regional development from 1940 to 1950, but there has been no deeper exploration of the activities and methods used by the service. An evaluation is essential to identify the concept of health and development that underpinned its practices and its conditions for sustainability. The service's contribution must be framed within its established relation with the population, who benefited from the developmental changes achieved by the agency, although it changes health practices, customs, and cultural values and re-organized space, interfering with established temporalities and redefining prevailing territorialities.

Keywords: Special Public Health Service; preventive medicine; middle Doce River; culture; territoriality. 


\section{O médio rio Doce e a territorialização da saúde}

O levantamento prévio da situação sanitária da região do médio rio Doce em fontes documentais nos mostra uma dinâmica sociossimbólica, sociocultural e econômica com a atuação de diversos atores sociais. Todo o processo de territorialização da modernização da saúde se estabeleceu de forma intrinsecamente atrelada aos processos históricos de ocupação e exploração desse território, na primeira metade do século XX, conforme Vilarino (2008). Para esse levantamento, foi considerada a documentação existente na Casa de Oswaldo Cruz/Fundação Oswaldo Cruz (COC/Fiocruz) ${ }^{1}$, no Centro de Documentação e Arquivo de Custódia/Univale², além de periódicos (Revista do Serviço Especial de Saúde Pública, o semanário Voz do Rio Doce e o Diário do Rio Doce). Consideramos também a coleta de trinta testemunhos, entre funcionários e contemporâneos que acompanharam a atuação do Serviço Especial de Saúde Pública (Sesp). ${ }^{3}$

Nesse processo de territorialização, o povoamento ocorrido de forma mais contundente nas quatro primeiras décadas do século XX remete a um panorama que permite a distinção de dois grupos de 'povoadores do Vale do rio Doce': (a) um que se assenhora das terras e da riqueza, com amparo legal, aliás, os autodenominados pioneiros; e (b) outro, maior, de trabalhadores de várias especialidades (agricultores, oleiros, canoeiros, carpinteiros, cortadores de madeira, outros trabalhadores braçais) e suas famílias - ao fim e ao cabo, os brasileiros que careciam de assistência médica, provimento de equipamentos e educação sanitária. Foi em meio a essa população que o Sesp atuou. Com base nos registros daquilo que o Serviço declara ter feito e do que a população declara ter recebido e internalizado ponderaremos sobre o processo em foco.

Em outras palavras, esta nota de pesquisa enfoca uma experiência de saneamento oriunda de acordo entre Brasil e EUA, com o intuito de garantir condições básicas de saúde que propiciassem a extração de minérios utilizados em equipamentos bélicos na Segunda Guerra Mundial. A partir de narrativas de funcionários do Sesp e de contemporâneos seus não funcionários, novas nuanças, até então obscurecidas, sobre o processo de territorialização da saúde e do saneamento nessa região serão consideradas.

\section{Os cuidados com a saúde em diversas narrativas}

As referências ao Sesp nos textos de memorialistas locais e no depoimento dos antigos funcionários tratam-no com a deferência dirigida a autoridade ou benfeitor; são comuns os elogios à sua atuação e à proposta de ação 'moderna' em relação à saúde e ao saneamento de áreas urbanas e rurais (Castro, 1951; Soares, 1983; Fonseca, s.d.). Tais menções são afirmativas da capacidade e da competência do Serviço e de seus técnicos, dos benefícios realizados para as cidades e as populações atendidas, tais como erradicação da malária, tratamento de outras enfermidades e implantação de serviços para o tratamento de água e esgoto. Nesses discursos, a ação do Sesp é digna dos melhores louvores, e são raros os questionamentos críticos, como o publicado no semanário valadarense Voz do Rio Doce, em 1947, afirmando ser a instituição pura fachada de 'macaquitos' metidos a yankee. Em trabalhos acadêmicos mais recentes sobre o médio rio Doce, a ação do Sesp é reconhecida 
como um dos fatores que impulsionaram o desenvolvimento regional nas décadas de 1940 e 1950. A relação estabelecida entre o Sesp e o desenvolvimento do médio rio Doce, contudo, aparece de forma pontual, sem que haja um aprofundamento nas atividades realizadas ou nos métodos utilizados.

Nesse sentido, verificar o contexto de constituição do Sesp e a concepção de saúde e de desenvolvimento subjacente a suas práticas, bem como as condições de sua manutenção até 1960, por meio de acordo com os EUA, tornou-se fundamental para avaliar sua atuação no médio rio Doce. As metodologias de intervenção que acompanharam a execução dos projetos de saneamento e de assistência médica se relacionaram com a concepção do 'círculo vicioso da doença e da pobreza' e com uma pedagogia sanitária em que a responsabilidade individual sobrepuja a responsabilidade política (Fontenele, 1959; Strauch, 1955; Almeida, 1959; Fonseca, s.d.). As duas tendências observadas nos relatórios e nas publicações do Sesp enfatizam o tripé ignorância-pobreza-apatia como causa do agravamento do quadro nosológico e o entendimento da saúde como fator de desenvolvimento econômico. Nesse aspecto, anunciam mas não esclarecem as interferências das condições sociais sobre a propagação de doenças. Essa concepção parte da suposição de que certos hábitos, costumes e sistemas de crenças populares, bem como processos de cura a partir da medicina rústica, são manifestações de ignorância e superstição. Os relatos e imagens que os sanitaristas Belizário Penna e Arthur Neiva divulgaram sobre as populações do interior do Brasil foram reapropriadas por diversos intelectuais em suas interpretações do Brasil e reforçaram essa tese (Lima, 1998).

Para o médio rio Doce, as ações do Sesp nas décadas de 1940 e 1950 propiciaram o ordenamento dos territórios urbanos, o saneamento rural, a erradicação da malária, a contenção de outras endemias e a imposição das práticas médicas científicas. Dessa forma, foram criadas as condições territoriais para a região receber e expandir os grandes investimentos de capital (mineração, siderurgia, indústria madeireira), confirmando-a ao mesmo tempo como fronteira agrícola (expansão da pecuária de corte e produção agrícola), e reafirmando o papel do Serviço na consolidação e no fortalecimento da presença do Estado (state building) nessa região, conforme Espindola (2005).

Para a população atendida tais ações provocaram alterações nas práticas de saúde, nos costumes e nos valores culturais, bem como a reorganização do espaço. O discurso de ciência em que o Sesp se apoiava procurava sistematizar uma pedagogia sanitária de intervenção na comunidade, que se opunha às estratégias que a comunidade utilizava para lidar com as doenças. A atuação, portanto, evidencia o objetivo de preparar as gerações mais novas segundo os padrões científicos e, simultaneamente, combater as práticas da medicina popular. Nessa dinâmica, as visitadoras, as auxiliares de atendimento e os guardas sanitários se apropriaram do discurso técnico-científico e iniciaram um processo de autorreconhecimento como agentes de mudança 'por dentro', ou seja, como membros das comunidades atendidas ou que tinham perfil equivalente, conforme em geral ficou implícito nos depoimentos concedidos.

Para nossos informantes, antigos funcionários, o Sesp foi uma benesse do poder público, confirmando a tese de que a disponibilização de bens públicos de saúde não foi usufruída como conquista social. A população atendida pelo Sesp ainda está por ser ouvida, auscultada. 
De mais a mais, ainda não se cumpriu no médio rio Doce, tampouco no Brasil, a meta estampada no selo comemorativo de 1960, por ocasião da transformação do Serviço em Fundação Sesp, de responsabilidade de dom Basílio Penido, médico e monge beneditino: Salubritas ubique curanda, isto é, seja a saúde promovida por toda parte.

Por outro lado, o segundo grupo de informantes, formado por contemporâneos sem ligação direta com o Sesp, oferece panorama bem diferente, no qual a benesse, quando é usufruída nem sempre apresenta igual caráter transformador. Tal fato pode ser exemplificado com o caso do paciente que fez o exame, mas, por falta de orientação, não levou o resultado ao médico para ser devidamente medicado. Em outros, o Serviço nem sequer foi referido, e, quando as narrativas sobre o cotidiano tocam a questão das endemias e das dificuldades sanitárias, os informantes não se referem diretamente ao Sesp como agente transformador. O curioso é que o esquecimento tanto esteve presente nas narrativas daqueles que se encontravam mais afastados das áreas de mais intensa atuação sespiana quanto nas áreas mais próximas.

\section{A questão sanitária e sua transversalidade}

É nesse sentido que podemos falar de um objeto transversal. A questão sanitária perpassa os meandros do território físico, demarcado na região do médio rio Doce de acordo com os documentos oficiais, mas também remete a outra concepção de território, imerso em um contexto sócio-histórico, cercado por inúmeras relações de poder que vão desde as estabelecidas entre os habitantes autóctones e os 'pioneiros' àquelas que vinculavam os interesses norte-americanos à região. Essa segunda concepção de território, de cunho relacional, mostra dimensão mais apurada das territorialidades ${ }^{4}$, que ora se chocavam, ora se complementavam no processo de saneamento em desenvolvimento, principalmente nas áreas centrais em direção à periferia de Governador Valadares, mas também em outros centros atendidos (Haesbaert, 2006; Saquet, 2006). Simbolicamente, o território atendido pelo Sesp era visto de forma global e incluía a cidade, mas, em função das múltiplas territorialidades, a realidade fornecia novos contornos aos projetos executados. As informações e a educação sanitária pretendida pelo Sesp não desconfiguravam as práticas cotidianas da população da periferia que, embora assistida, mantinha seus costumes (Oberg, 1958).

A territorialidade dominante dos 'pioneiros' de Governador Valadares - que podemos tomar como centro exemplar em relação às demais cidades do médio rio Doce -, revestida de modernidade, se sobrepunha à da população menos abastada, que em muitos aspectos não contestou o discurso civilizador, mas apenas internalizou o que sinalizavam seus atores mais significativos, oriundos das famílias ilustres e bem-sucedidas (Hobsbawm, Ranger, 1984). Ao elevar os 'pioneiros' à categoria de heróis locais, os memorialistas cumpriram seu papel na seleção do que deveria ser lembrado e do que teria que ser esquecido, como realça Ricoeur (2007). Daí a importância de se trabalhar a partir da interação entre a memória coletiva e a individual, abrindo espaço para a compreensão da sociedade e buscando as conexões e a significação cultural da realidade da vida que nos rodeia. A ação social de cada agente envolvido no processo apresenta um sentido manifestado na concretude da cadeia motivacional que se forma, conforme observado (Cohn, 1991). Nessa 'teia de 
significados' (Geertz, 1978), cabe interpretar os motivos do Sesp realçados nas palavras de seus antigos funcionários e o sentido cotidiano dessa mesma ação (Labov, 2001; Rapport, 1998). Cabe, ainda que de forma indiciária, ponderar sobre as negociações dessas narrativas amarradas nos vários discursos, entre os quais o dos documentos oficiais e aqueles revelados pelo Diário do Rio Doce, que recorrentemente expunha o caos sanitário vivenciado pelos moradores (Rapport, Overing, 2000).

Por isso, o território multifacetado que se apresenta exige da análise histórica um esforço contínuo de contraponto entre suas várias escalas espaciais e temporais. Numa perspectiva mais ampla, a ação sespiana não pode ser enquadrada numa estrutura, posto que não se pode referir ação homogênea. Estamos, portanto, lidando com um agenciamento, cujo conjunto de partes interage negociando sentidos e configurando ações e intenções (Haesbaert, 2006).

Nessa multiterritorialidade a modernidade dos 'pioneiros' não tem sentido igual para os demais habitantes, e nem mesmo a urbanização e o desenvolvimento empreendidos, a partir dos projetos implementados pelo Sesp, serão incorporados ao cotidiano de forma semelhante. O Sesp tinha como modelo de saneamento o padrão internacional; a maioria da população tinha como modelo o próprio vizinho, que muitas vezes podia ridicularizar o uso da fossa sanitária. O reordenamento do espaço urbano, já mencionado, embora alterasse visivelmente o território, não desagregava as práticas de manter o lixo nas ruas, de usar o mato para as necessidades fisiológicas e as fossas para guardar arreios e galinhas; tampouco de julgar a água do rio Doce mais confiável do que aquela que chegava através de um sistema de abastecimento.

\section{Considerações finais}

Em função do exposto, a ação do Sesp deve ser analisada levando-se em consideração os vários discursos e as múltiplas territorialidades constituídas a partir da documentação pesquisada. Partindo desses pressupostos, nos posicionamos diante de um território que ganha dinâmica e sentido de acordo com a apreensão da conduta dos múltiplos agentes e dos significados que sua ação venha a alcançar. É necessário, para tanto, estender a análise à antropologia interpretativa de Geertz (1978), que compreende cultura como uma 'teia de significados'. Nas palavras do autor, "acreditando, como Max Weber, que o homem é um animal amarrado a teias de significados que ele mesmo teceu, assumo a cultura como sendo essas teias e a sua análise; portanto, não como uma ciência experimental em busca de leis, mas como uma ciência interpretativa, à procura do significado" (p.15). Todo esse processo ocorre mediante negociação dos significados por meio da interpretação narrativa, armazenada por uma comunidade (Bruner, 1997, p.65).

Nas palavras de Saquet (2006, p.83), "o território é processual e relacional, (i)material, com diversidade e unidade, concomitantemente". Nele se estabelecem as mais variadas escalas geográficas e até temporalidades diferentes. Neste exercício, ao abordar o processo de territorialização da saúde e do saneamento a partir da memória oral e documental referente ao Sesp, podemos sugerir, de forma complementar, que em meio a essas operações espaciais e temporais, o território também comporta diversas narrativas, lembranças e 
esquecimentos, apreensões, sentidos, intenções e representações, em incessante busca de conciliar as múltiplas temporalidades num processo territorial multiescalar e repleto de multiterritorialidades. Enfim, não há como negar a contribuição do Sesp que, entretanto, deve ser repensada em dimensão mais ampla, considerando-se a relação estabelecida com a população. Para a população atendida, as ações sespianas trouxeram o desenvolvimento, mas provocaram alterações nas práticas de saúde, nos costumes e nos valores culturais, bem como (re)organização do espaço, interferindo nas temporalidades estabelecidas e redefinindo as territorialidades exercidas.

\section{NOTAS}

${ }^{1}$ Arquivo da Casa de Osvaldo Cruz/Fiocruz. Fundo Sesp. Subsérie Documentos Diversos; subsérie Cursos, Treinamentos e Publicações; Série Assistência Médico-Sanitária; Série Engenharia Sanitária/Saneamento Básico; Série Engenharia Sanitária/Subsérie Saneamento Ambiental; Série Engenharia Sanitária/Construções Civis.

${ }^{2}$ Centro de Documentação e Arquivo de Custódia (Cedac/Univale). Fundo: Prefeitura Municipal de Governador Valadares (PMGV) 1/1. Série 1 - Infraestrutura urbana Subséries 1 a 9.

${ }^{3}$ Entrevistas concedidas à professora Maria Terezinha Bretas Vilarino de 2007 a 2009, arquivadas no Programa de Memória do Vale do Rio Doce (PMVRD/Univale).

${ }^{4}$ Sobre o conceito de territorialidade, ver Sack, 1986, p.213-220). A territorialidade é uma tentativa, ou estratégia, de um indivíduo ou de um grupo para atingir, influenciar ou controlar recursos e pessoas por meio da delimitação e do controle de áreas específicas - os territórios. Em termos gerais, essa delimitação só se torna território quando seus limites são utilizados para influenciar o comportamento das pessoas pelo controle de acesso de seus limites. A partir desse entendimento, os territórios possuiriam diferentes níveis de permeabilidade, ou de acessibilidade, às pessoas, aos objetos ou aos fluxos dos mais diferentes tipos. Lembramos que Sack explicita a possibilidade de os territórios serem fixos no espaço, mas alguns podem mover-se - territórios móveis. A partir desses pressupostos, uma área para ser território necessita de esforço constante visando manter as estratégias para influenciar e controlar o acesso através de seus limites; quando elas cessam, o atributo territorial também cessa. O conceito presta-se a análises em diferentes escalas e normas de conduta e de convivência. De forma ampla, Robert Sack (p.219) considera que "a territorialidade, como uma componente do poder, não é somente um meio de criação e manutenção da ordem, mas é um instrumento para criar e manter muito do contexto geográfico através do qual vivenciamos o mundo e lhe damos significado" (tradução livre).

\section{REFERÊNCIAS}

ALMEIDA, Ceciliano Abel de.

O desbravamento das selvas do rio Doce. Rio de Janeiro: José Olímpio. 1959.

BRUNER, Jerome.

Atos de significação. Porto Alegre: Artes Médicas. 1997.

CASTRO, Siva Monteiro de. Perspectiva do vale do rio Doce. Revista Acaiaca, Belo Horizonte, n.32 (especial), nov., p.35-36. 1951.

COHN, Gabriel. (Org.)

Max Weber. São Paulo: Ática. 1991.

ESPINDOLA, Haruf Salmen.

Sertão do rio Doce. Bauru: Edusc. 2005.
FONSECA, Raymundo José.

Figueira do rio Doce: notas nativas. Belo Horizonte: Fundação João Pinheiro, s.d.

FONTENELE, Luiz Fernando Raposo. Aymorés: análise antropológica de um programa de saúde. Rio de Janeiro: Dasp/ Serviço de documentação. 1959.

GEERTZ, Clifford. A interpretação das culturas. Rio de Janeiro: Zahar. 1978.

HAESBAERT, Rogério.

O mito da desterritorialização: do "fim dos territórios" à multiterritorialidade. Rio de Janeiro: Bertrand Brasil. 2006. 
HOBSBAWM, Eric; RANGER, Terence. A invenção das tradições. Rio de Janeiro: Paz e Terra. 1984.

\section{LABOV, William.}

Uncovering the event structure of narrative. Georgetown University Round Table, Georgetown, p.63-83. 2001.

LIMA, Nísia Trindade.

Missões civilizatórias da República e

interpretação do Brasil. História, Ciências, Saúde

- Manguinhos, Rio de Janeiro. v.5, supl., p.163-198, jul. 1998.

OBERG, Kalervo.

Chonim de Cima: a rural community in Minas Gerais, Brazil. Rio de Janeiro: Usom/Brazil. 1958.

RAPPORT, Nigel.

Problem-solving and contradiction. Playing darts and becoming human. Self, Agency and Society, Derby, v.2, n.1, p. 81-101. 1998.

RAPPORT, Nigel; OVERING, Joanna. Narrative. In: Rapport, Nigel; Overing, Joanna. Social and cultural anthropology: key concepts. London: Routledge. p. 283-290. 2000.
RICOEUR, Paul.

A memória, a história, o esquecimento. Campinas: Editora da Unicamp. 2007.

SACK, Robert.

Human territoriality: its theory and history. Cambridge: Cambridge University. 1986.

SAQUET, Marco Aurélio.

Proposições para estudos territoriais. GEOgrafia, Niterói, ano 8, n.15, p. 71-85. 2006.

SOARES, Ruth.

Memórias de uma cidade. Governador Valadares: S/A Tribuna Fiel. 1983.

STRAUCH, Ney.

A bacia do rio Doce: estudo geográfico. Rio de Janeiro: Instituto Brasileiro de Geografia e Estatística/Conselho Nacional de Geografia. 1955.

VILARINO, Maria Terezinha Bretas.

Entre lagoas e florestas: atuação do Serviço Especial de Saúde Pública no vale do rio Doce entre 1942 e 1960. Dissertação (Mestrado) Faculdade de Filosofia e Ciências Humanas, Universidade Federal de Minas Gerais, Belo Horizonte. 2008. 